\title{
Exosomes derived from cancerous and non-cancerous cells regulate the anti-tumor response in the tumor microenvironment
}

\author{
Susan Bae ${ }^{1, *}$, Jeffrey Brumbaugh ${ }^{1, *}$ and Benjamin Bonavida ${ }^{2}$ \\ ${ }^{1}$ Department of Oral Biology, UCLA School of Dentistry, University of California, Los Angeles, CA, USA \\ ${ }^{2}$ Department of Microbiology, Immunology \& Molecular Genetics, David Geffen School of Medicine, University of California, \\ Los Angeles, CA, USA \\ * These authors have contributed equally to this review \\ Correspondence to: Benjamin Bonavida, email: bbonavida@mednet.ucla.edu \\ Keywords: angiogenesis, exosomes, immunoregulation, immunotherapy, tumor-derived exosomes \\ Received: March 02, $2018 \quad$ Accepted: May 27, $2018 \quad$ Published: June 05, 2018
}

Copyright: Bae et al. This is an open-access article distributed under the terms of the Creative Commons Attribution License 3.0 (CC BY 3.0), which permits unrestricted use, distribution, and reproduction in any medium, provided the original author and source are credited.

\section{ABSTRACT}

The tumor microenvironment (TME) is a unique platform of cancer biology that considers the local cellular environment in which a tumor exists. Increasing evidence points to the TME as crucial for either promoting immune tumor rejection or protecting the tumor. The TME includes surrounding blood vessels, the extracellular matrix $(E C M)$, a variety of immune and regulatory cells, and signaling factors. Exosomes have emerged to be molecular contributors in cancer biology, and to modulate and affect the constituents of the TME. Exosomes are small (40-150 $\mathrm{nm})$ membrane vesicles that are derived from an endocytic nature and are later excreted by cells. Depending on the cells from which they originate, exosomes can play a role in tumor suppression or tumor progression. Tumor-derived exosomes (TDEs) have their own unique phenotypic functions. Evidence points to TDEs as key players involved in tumor growth, tumorigenesis, angiogenesis, dysregulation of immune cells and immune escape, metastasis, and resistance to therapies, as well as in promoting anti-tumor response. General exosomes, TDEs, and their influence on the TME are an area of promising research that may provide potential biomarkers for therapy, potentiation of anti-tumor response, development of exosome-based vaccines, and exosome-derived nanocarriers for drugs.

\section{INTRODUCTION}

Amid the complexities of cancer in its development, growth, and metastasis, the tumor microenvironment (TME) is a unique platform of cancer biology that controls the local cellular environment in which a tumor exists. The TME is currently a very significant field of research, as increasing evidence points to the TME as pivotal for either promoting immune tumor rejection or protecting the tumor [1]. Thus, the TME may provide stimulatory factors that enhance tumor response and rejection. In contrast, the TME can also provide tumor cells with resistance mechanisms against therapeutic chemo and immune interventions, such as reducing drug penetration, conferring antiapoptotic advantages to cytotoxic immune cells, and withstanding genetic mutations [2-4]. Comprised of various cellular and non-cellular factions, the TME includes surrounding blood vessels, the extracellular matrix (ECM) and myofibroblasts, a variety of immune and regulatory cells, and a mix of signaling factors and cytokines directed against both immune cells and nonimmune cells [2].

As one of the main components of the TME, tumor vasculature has been described as a defining characteristic of regulating cell growth and metastasis. In fact, sustained angiogenesis is considered one of the hallmarks of cancer, a term coined by Hanahan and Weinberg in their seminal article outlining the six key traits of cancer [5]. In normal 
tissue, the vasculature provides oxygen and nutrients required for cell growth, obligating nearly all cells to reside within 100 micrometers of a capillary vessel [5]. In the TME, however, vasculature is poorly organized, promoting hypoxia and limited growth factor feeding [3]. The reduced capability of tumor vasculature to effectively deliver molecules to the stroma is one of the challenges in providing anti-tumor agents as targeted therapies [6, 7].

The interstitial stroma of the TME is another contributing factor in tumor growth and development. It has been demonstrated that the ECM of tumors includes tissue rich in myofibroblastic cells, which are capable of supporting tumor progression, promoting angiogenesis, and providing protection against drugs [8, 9]. Normal stromal fibroblasts are transformed into cancer-associated fibroblasts (CAFs) through interactions with nearby cancer cells. These CAFs exhibit a unique phenotype of increased expression of ECM components and inflammatory cytokines [10]. CAFs can also develop a myofibroblastic phenotype, with the expression of smooth muscle cell markers, such as $\alpha$-smooth muscle actin, and the production of transforming growth factor $\beta$ (TGF$\beta)[10,11]$. The migration stimulating factor (MSF) and focal adhesions have been shown to contribute to an activated TME and the differentiation of cancer-associated myofibroblasts $[10,12]$. MSF, as a potent mitogenic factor, promotes the migration of fibroblasts and endothelial cells in the TME and metabolically regulates stromal fibroblasts towards a glycolytic and tumor-promoting metabolism [10].

Multiple types of cells and cellular infiltrates can be found dispersed throughout the TME, and immune cells are certainly the majority of these cells. Monocytes, macrophages, T cells, B cells, myeloid cells, and natural killer (NK) cells are all encountered in the TME and play complex roles in immune activation, immune suppression, surveillance, tumor growth and metastasis, depending on the factors at hand [13-15].

Exosomes, an emerging molecular contributor in cancer biology, modulate and affect the TME and the well-established components of the TME - tumor vasculature, the ECM and myofibroblasts, and an assortment of immune cells. Tumor-derived exosomes (TDEs), in particular, are extracellular vesicles released from tumor cells, unique in their functions and origins $[16,17]$. Evidence points to TDEs as key players involved in tumor growth, tumorigenesis, angiogenesis, immune escape, metastasis, and resistance to therapies [16, 18]. The present review will focus on both non-cancerous exosomes and TDEs, and their influence on the TME as an area of promising research providing potential biomarkers for therapy, reversing immune resistance, developing exosome-based vaccines, and generating exosome-derived nanocarriers for drugs $[15,16,19,20]$.

\section{Exosomes}

\section{Properties}

Exosomes are small (40-150 nm) membrane vesicles that are endocytic in origin and are released into the extracellular environment upon fusion with the plasma membrane [21-23]. Proteomic analysis of exosome profiles has uncovered their distinct entity and functions, which have helped to provide a theory of their biogenesis, namely, from multivesicular endosomes [24]. The physical properties of exosomes rely upon their purification from cell culture supernatants through differential centrifugation followed by sucrose density gradients [25]. Subsequently, further analyses are done through western blot, fluorescence-activated cell sorting (FACS), trypsin digestion, or peptide mapping by matrix-assisted laser desorption ionization-time of flight (MALDI-TOF) mass spectrometry (Figure 1) [26]. The exosomal protein profile is similar to that of molecules found in the endocytic pathway, plasma membrane, or cytosol. The cytosolic proteins that are involved in exosome biogenesis and function are mainly cytoskeleton-related (e.g. cofilin, profilin I) and signaling factors (e.g. rab 7, syntenin) [26]. The exosomal proteins are found on the cell surface and in endocytic vesicles, such as the CD9 cell surface protein in dendritic cells [26]. Despite having plasma membrane proteins, exosomes do not express cell surface proteins such as CD28 and CD45 (lymphocyte common antigen) in T-cell derived exosomes and types II/III Fc receptors in dendritic cell-derived exosomes [26, 27]. In addition, cytosolic proteins found in the exosomes are also present in the endocytic pathway, such as rab5/7 [28]. Exosomes are formed from inward budding of multivesicular endosomes that fuse with the plasma membrane resulting in the discharge of the exosomes into the extracellular environment [28-30]. The multivesicular endosomes are regulated by the endosomal sorting complexes required for the transport (ESCRT) pathway and the excretion of the exosomes controlled by Rab GTPases 27a and 27b [31-33].

\section{Composition}

The composition of exosomes can vary depending on the cell from which they originate. Many cells have the ability to release exosomes, including epithelial cells, tumor cells, and various immune cells, such as dendritic cells, B cells, T cells, and mast cells [21, 34]. Exosomes from mast cells have been shown to carry both mRNAs and microRNAs (miRNAs) that can be genetically 
Table 1: Exosomal cargo affecting tumorigenesis

\begin{tabular}{|l|l|c|}
\hline \multicolumn{1}{|c|}{ Exosome protein } & \multicolumn{1}{c|}{ Cell type } & References \\
\hline$\beta 1, \beta 2$ integrins & B lymphocytes & {$[34]$} \\
\hline EGFRvIII & Gliomas & {$[38]$} \\
\hline EpCAM & Carcinoma cells & {$[39]$} \\
\hline CD24 & Carcinoma cells & {$[39]$} \\
\hline Mart-1 & Melanoma cells & {$[28]$} \\
\hline Mel-CAM & Melanoma cells & {$[28]$} \\
\hline MHC class I A \& B & Cervical cancer cells & {$[49]$} \\
\hline ICAM-1 & Prostate cancer cells & {$[52]$} \\
\hline Galectin-1 & Carcinoma cells & {$[64]$} \\
\hline VEGF & Red blood cells & {$[69]$} \\
\hline miR-214 & Endothelial cells & {$[70]$} \\
\hline lncRNA & Ovarian carcinoma cells & {$[73]$} \\
\hline Tspan8 & Adenocarcinoma cells & {$[74]$} \\
\hline miR-21, 37e, 143 & CAFs & {$[78]$} \\
\hline Wnt10b & CAFs & {$[79]$} \\
\hline
\end{tabular}

Exosomes influence the TME by driving tumorigenesis. exchanged between cells resulting in a specific protein production in the recipient cell [21]. In addition, it has been shown that the Major Histocompatibility Complex Class II molecules (MHC II) can be released by exosomes from mast cells and B cells $[25,35]$. Tumor-derived exosomes contain tumor-associated antigens, which can be used to stimulate CD8 T cells for cross priming in immunotherapy [30]. The transfer of these contents is specific to ligands or signals on the recipient cells and exosomes. For example, exosomes from B lymphocytes express $\beta 1$ and $\beta 2$ integrins that adhere to fibroblasts [36]. Exosomes can bind to target cells through receptor-ligand interactions or by adhering to lipids on the cell membrane and can also be completely internalized by endocytosis or fused with the cell surface membrane $[22,37,38]$.

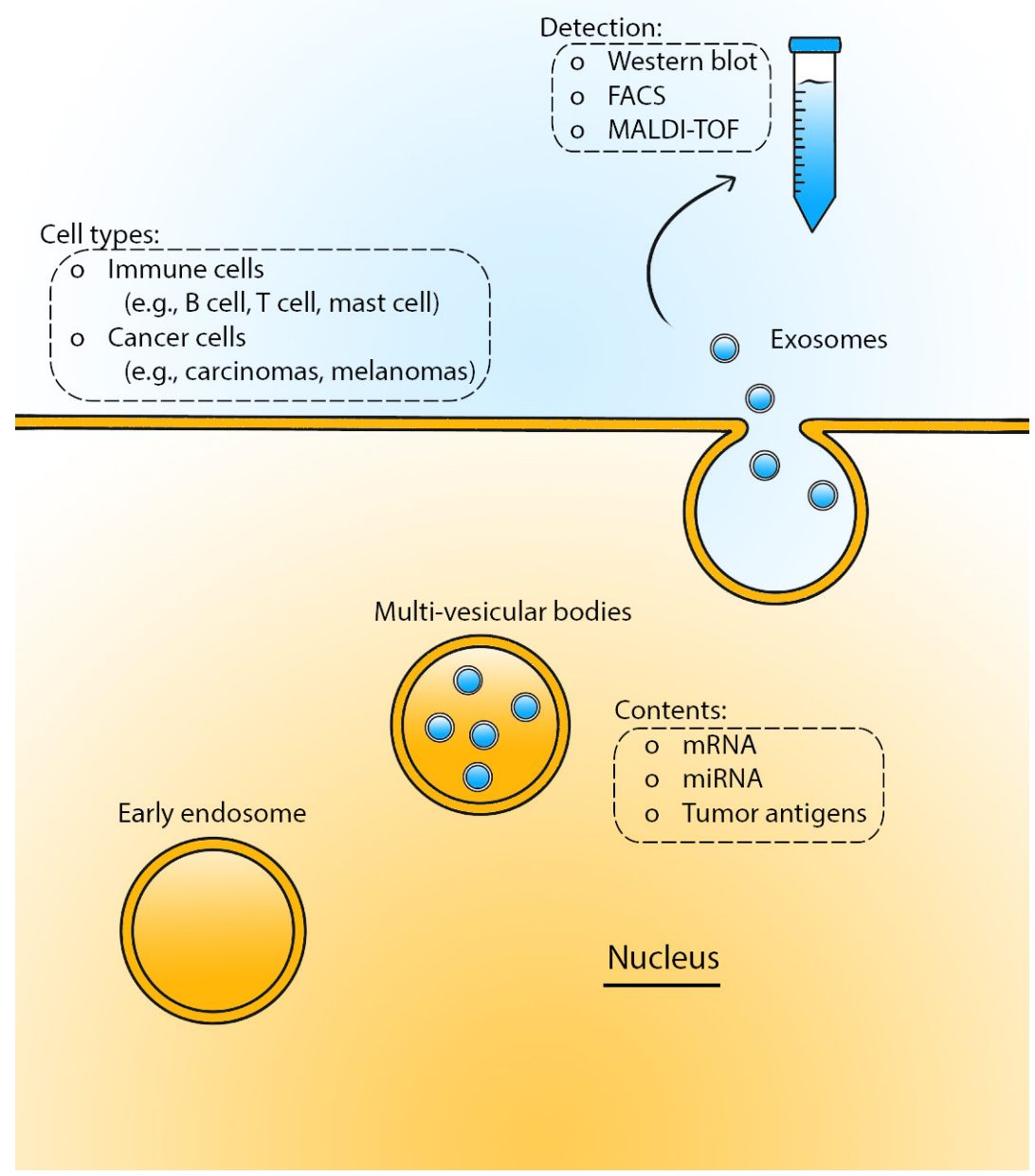

Figure 1: Exosome production and detection. Exosomes are small (50-90 nm) membrane vesicles that are endocytic in origin and are released into the extracellular environment upon fusion with the plasma membrane. They are formed by multi-vesicular bodies, which release the exosomes into the surrounding environment. Isolation of exosomes is performed through differential centrifugation, from which the contents are then analyzed through Western Blog, FACS, and MALDI-TOF. Various cell types, including immune cells and cancer cells, release exosomes carrying a multitude of cargo, including but not limited to as microRNAs, mRNAs, and tumor antigens. 
Table 2: Exosome-based applications and therapies in cancer

\begin{tabular}{|c|c|c|}
\hline $\begin{array}{c}\text { Immune Cell Derived Exosomes } \\
\text { Activities }\end{array}$ & Pros & Cons \\
\hline $\begin{array}{l}\text { DC-derived } \\
\text { NK-derived } \\
\text { MDSC-derived }\end{array}$ & $\begin{array}{ll}\text { Improved TME by increased CD8+ T } \\
\text { cells, IFN- } \gamma \text {, and IL-2 } \\
\text { Decreased Treg cells, IL-10, and } \\
\text { TGF- } \beta \text { in tumor sites } \\
\text { Perforin and Fas } 1 \text { lead to apoptosis } \\
\text { in melanoma } \\
\text { Potential target of anti-tumor } \\
\text { therapies }\end{array}$ & $\begin{array}{l}\text { Challenges in vesicle engineering and } \\
\text { delivery } \\
\text { Challenges in vesicle engineering and } \\
\text { delivery } \\
\text { miR-126a exosomes lead to increased } \\
\text { IL-13 expression and angiogenesis in } \\
\text { tumors } \\
\text { Challenges in vesicle engineering and } \\
\text { delivery }\end{array}$ \\
\hline TDEs & $\begin{array}{l}\text { Decreased tumor proliferation via } \\
\text { NOTCH1 pathway }\end{array}$ & $\begin{array}{ll}\text { - } & \text { Contains tumor-promoting signals like } \\
\text { IGF-1R, FAK, and Src } \\
\text { - } & \text { Promotes angiogenesis (linc CCAT2) }\end{array}$ \\
\hline Nanocarriers & $\begin{array}{ll}- & \text { Cross difficult membranes (Blood } \\
\text { brain barrier) } \\
\text { - } & \text { Delivery of gene therapy } \\
\end{array}$ & $\begin{array}{l}\text { - } \quad \text { Proper design is a challenge } \\
\text { - } \quad \text { Need to avoid immune response }\end{array}$ \\
\hline Diagnostics & \begin{tabular}{ll|}
- & Highly homologous \\
mRNA offers stability and specificity \\
during collection
\end{tabular} & \begin{tabular}{|l|}
$-\quad \begin{array}{l}\text { Cannot distinguish disease severity } \\
\text { Difficult isolation of other exosomal } \\
\text { cargo }\end{array}$ \\
\end{tabular} \\
\hline
\end{tabular}

Advantages and disadvantages of exosome-based therapies, including immune cell derived exosomes and TDEs, and exosomal applications as nanocarriers and in diagnostics are listed.

\section{Tumor-derived exosomes (TDEs)}

For cancer to metastasize, there has to be a constant communication between cancer cells and the distant host environment, and (TDEs) may contribute to this crosstalk by recruiting and reprogramming the TME [31]. Gliomas express the oncogenic epidermal growth factor receptor, known as EGFRvIII, that is exchanged between tumor cells by exosomes (Figure 2) [39]. Depending on the tumor cell origin, the contents of the TDEs vary. Exosomes from epithelial cancers contain the epithelial cell adhesion protein (EpCAM) and CD24, which are markers for poor prognosis in carcinomas [40]. Melanoma supernatants indicate the presence of exosomes containing melanoma antigen recognized by $\mathrm{T}$ cells 1 (Mart-1) and melanoma cell adhesion molecule (Mel-CAM) [30]. There is increasing evidence that exosomes can influence the TME by promoting angiogenesis and modulate the immune system in order to drive tumorigenesis (Table 1).

\section{Exosome-mediated immune regulation in the tumor microenvironment}

In the early stages of cancer development, the process of immune surveillance eliminates precancerous and malignant cells through an immune-mediated response [41]. When this process is disrupted, however, then the immune system can no longer reject precancerous cells, and a tumor develops [42]. In the TME, tumorderived exosomes are the mediators of intercellular communication, and as such, play a distinct role in the dysregulation of immune surveillance [13]. Considering the composition of TDEs - specifically RNAs, DNAs, and cytokines as vesicular contents - surrounding cells receive TDEs as signals to modulate their transcriptional and translational machineries $[13,21,43]$. To affect immune cells, TDEs can participate in both the direct and indirect antigen presentation to activate a CD8 $+\mathrm{T}$ cell response [38]. Direct presentation occurs as antigen-specific T cells directly engage an MHC-peptide complex on the TDE. On the other hand, indirect presentation involves the acquisition of antigen from the TDE by antigen presenting cells, like dendritic cells, which then process and present the antigen to CD8+ T cells [13]. The mechanism of activation of CD4+ T cells is less understood, although TDEs have been shown to directly activate primed, but not naïve, CD4+ T cells [44]. As such, TDEs carrying either native tumor antigen or an MHC-peptide complex have been shown to be key players in antigen presentation during immune surveillance $[42,45,46]$.

Through their intercellular signaling abilities and antigen presentation, exosomes are capable of both evoking an anti-tumor immune response and promoting tumor growth through inhibition of anti-tumor immunity [13]. The promotion of an immune response relies on pro-inflammatory mediators, which can be excreted in exosomes from macrophages, $\mathrm{T}$ cells, and dendritic cells [47]. Distinct from tumor-derived exosomes, these immune cell-derived exosomes activate the immune response primarily through the TNF- $\alpha$ pathway, which may then induce epithelial cells to secrete other pro- 
inflammatory cytokines, such as IL-8, RANTES, and additional TNF- $\alpha$ [48]. Exosomes released from dendritic cells may also induce other immune cells, such as NK cells, in an anti-tumor response (Figure 3) [49].

On the other hand, the immune response is largely mediated through TDEs in tumor evasion and in the impairment of the function and regulation of immune cells, thus promoting a tumorigenic environment. Firstly, an evasion of the immune response requires TDEs to prevent tumor antigen recognition by immune cells. One way in which this occurs is through the release of MHC class I related chain (MIC) ligands A and B, which bind to NKG2D receptors on NK cells and prevent tumor recognition while simultaneously downregulating NKG2D receptor expression on NK cells and T cells [50, 51]. Another process involves minimizing the recruitment of adaptive immune cells, which can occur when a TDE-bound form of intercellular adhesion molecule -1 (ICAM-1) interferes with leukocytic binding to vascular endothelial cells $[52,53]$. Typically, ICAM-1 mediates leukocytic-endothelial binding to allow leukocytes to transmigrate into the tissue, but the exosomal form of ICAM-1 exhibits potent anti-binding properties [53].
Alternatively, TDEs can also induce decreased expression of CD3- $\zeta$ - a crucial T cell co-receptor - leading to a loss of $\mathrm{T}$ cell activation [54].

The second major mechanism through which TDEs inhibit the immune response lies in the dysregulation and dysfunction of immune cells. TDEs have been shown to interfere with monocyte differentiation into dendritic cells and directly interfere with dendritic cells' bioactivity [55]. Myeloid-derived suppressor cells (MDSCs) are formed from myeloid precursor cells, driven into differentiation via TDE cargo of TGF- $\beta$ and $\mathrm{PGE}_{2}[56,57]$. MDSCs then influence the immune response by producing immunosuppressive factors, such as nitric oxide and reactive oxidative species, and a secondary lack of DC cells needed for antigen presentation [58]. NK cells are another immune cell that TDEs may inhibit, with a decrease in their number and activity in the TME [59]. As previously mentioned, this is in part due to the binding and downregulation of the NKG2D receptor [51,60]. In T cells, TDEs can both impair the activation of CD8+ T cells and induce apoptosis of activated $\mathrm{T}$ cells. Interference with TCR- and IL-2R signaling impairs $\mathrm{T}$ cell activation [59], while TDE-bound FasL and exosomal TRAIL can

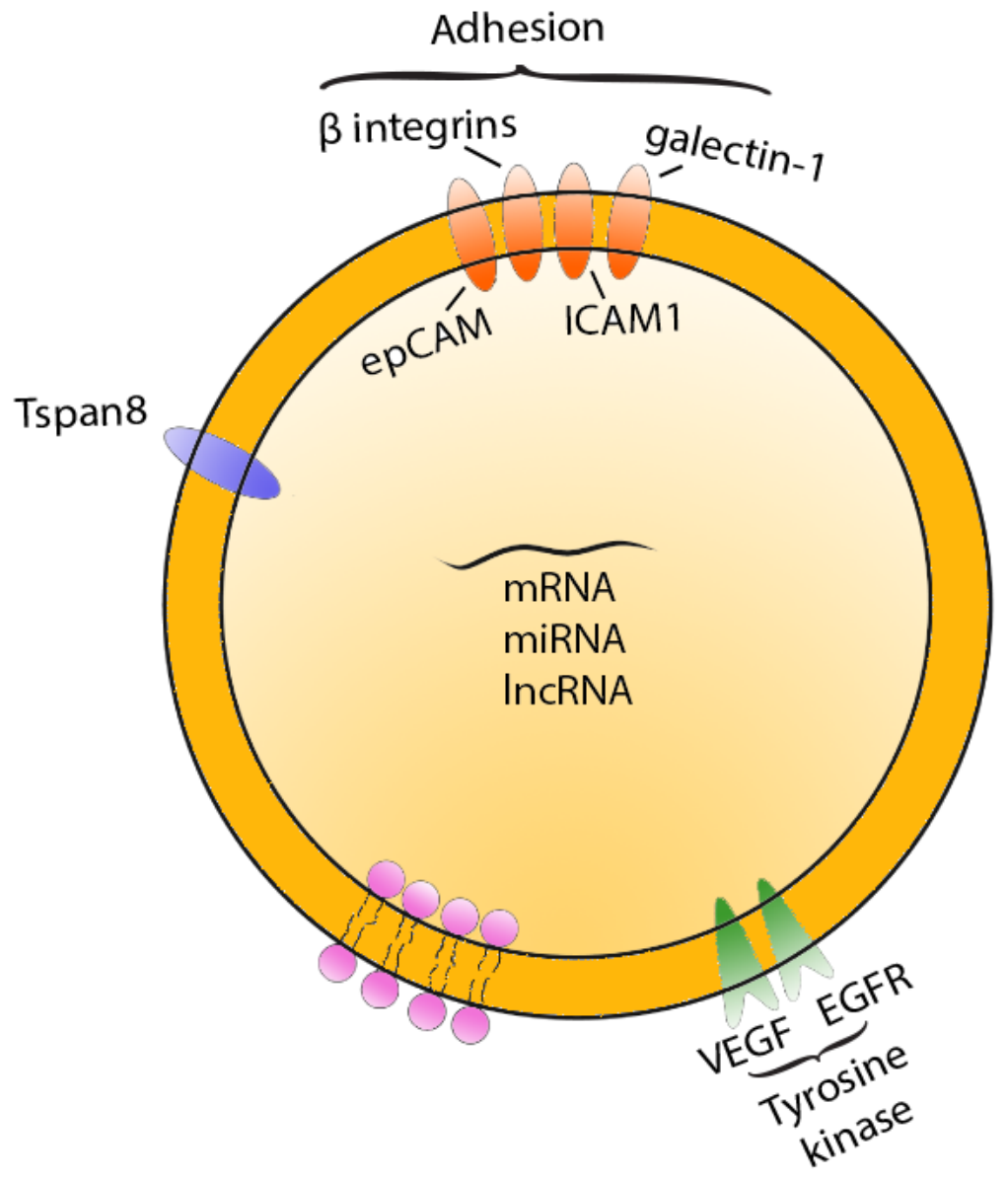

Figure 2: Tumor-derived exosome. Tumor-derived exosomes (TDEs) are aid in the recruitment and reprogramming of the TME. They express various oncogenic factors that enhance tumorigenesis. 
selectively induce apoptosis in T cells [61-64]. CD8+ $\mathrm{T}$ cells have also been shown to exhibit a suppressor phenotype, characterized by a loss of CD27/CD28 expression, mediated by galectin-1 found in TDEs [65]. The conversion of CD4+ T cells into Treg cells has also been shown to be mediated by TDEs through a TGF- $\beta 1$ pathway (Figure 3) [66].

\section{Exosomes crosstalk in the epithelium and the subepithelium in the TME}

Tumor-derived exosomes release contents and communicate with other cells, such as fibroblast cells that function in the subepithelium and endothelial cells that line the interior of blood vessels. Angiogenesis, which is required for invasive tumor growth and metastasis, is dependent upon the sprouting of endothelial cells [67,
68]. Vascular endothelial growth factor (VEGF) and its receptors VEGFRs are key factors that drive vasculature, with VEGFR2 being the main regulator of the angiogenic effect of VEGF $[69,70]$. When exosomes containing the miRNA 16/322/497/17 are co-cultured with endothelial cells, there is a decrease in the expression of VEGFR2 and subsequent inhibition of angiogenesis [70]. Conversely, when miR-214, which is found in tumor exosomes, is secreted by endothelial cells, it suppresses senescence and induces angiogenesis in endothelial cells [71].

Evidently, the exosomes can play a dual role, as they may participate in tumor suppression or promotion [72, 73]. But evidence suggests that tumor-derived exosomes promote angiogenesis in tumors. The epithelial ovarian cancer derived-exosomes can restore the migration of endothelial cells via the transfer of long non-coding RNAs (lncRNAs), which are RNA transcripts that are more than 200 nucleotides long but have been shown to be implicated

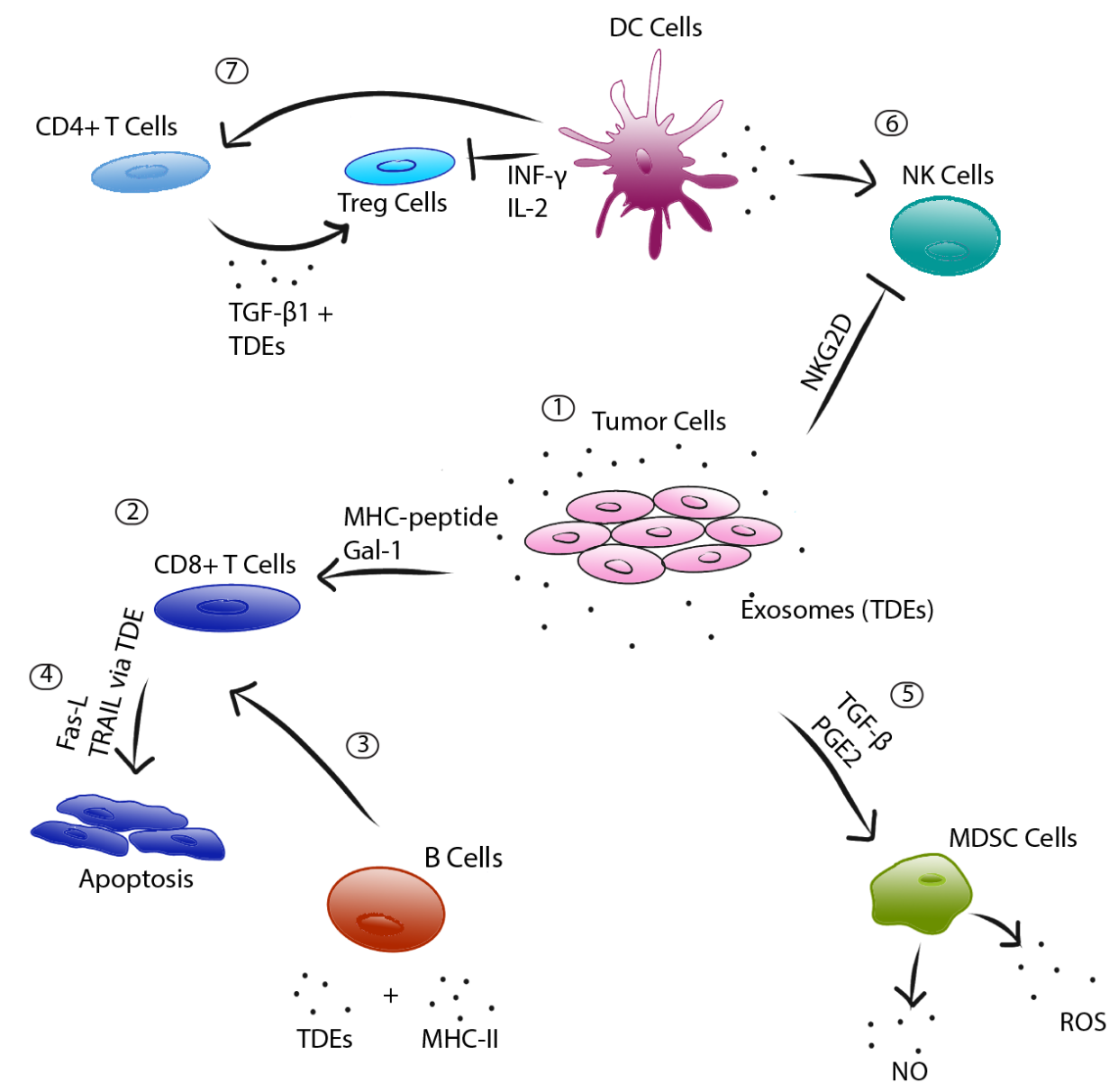

Figure 3: Exosome-mediated immune regulation. 1) Tumor cells release exosomes (TDEs) that consequently affect numerous immune cells. 2) MHC-peptide complexes participate in direct antigen presentation to activate a CD8+ T cell response. 3) TDE antigens combined with MHC Class II molecules released from B cells also serve to activate CD8+ T cells. 4) However, TDEs can also induce apoptosis of activated CD8+ T cells, via TDE-bound FasL and exosomal TRAIL. 5) TDEs also drive the differentiation, via TGF- $\beta$ and $\mathrm{PGE}_{2}$, of myeloid precursor cells to MDSCs, which release immunosuppressive factors NO and ROS. 6) Immune-cell derived exosomes, as from a dendritic cell, influence the TME and have been shown to boost NK cell immune response. However, TDEs combat this effect by downregulation of NKG2D receptors on NK cells. 7) DC-derived exosomes also stimulate CD4+ T cell response, which synergistically works with DC-derived exosomal cargo to inhibit Treg cells. 
in biological processes, such as gene expression [74]. Adenocarcinoma derived-exosomes containing Tspan8, which is a tetraspanin, induced angiogenesis by promoting VEGF-independent regulator of angiogenesis-related genes, such as chemokines CXCL5 and von Willebrand factor through the internalization of exosomes by endothelial cells [75]. Colorectal cancer-derived exosomes promote migration of endothelial cells by activating early growth response-1 (Egr-1) via the ERK1/2 and JNK signaling pathways [76].

Another cell involved in angiogenesis is the fibroblast, which produces growth factors, extracellular matrix, and chemokines that recruit endothelial cells [77]. The fibroblasts found in the tumor stroma are referred to as cancer-associated fibroblasts (CAFs) although their role in tumor progression is still unclear [78]. In breast cancer-derived exosomes, the exosomes in CAFs carry miRNAs $-21,-37$ e, and -143 , which are then released and promote a more aggressive phenotype of breast cancer by stimulating stemness and the epithelial mesenchymal transition (EMT), which is the loss of polarity and adhesion of epithelial cells into mesenchymal stem cells [79]. In breast cancer, $\mathrm{p} 85 \alpha$, which is a tumor suppressor, is downregulated [80]. The loss of p85a results in the transformation of fibroblasts in CAFs, which release exosomes containing Wnt10b that promote EMT induced by the canonical Wnt pathway [80]. In addition to release of content, the absence of content in CAF exosomes contributes to tumorigenesis. CAF-derived exosomes in hepatocellular carcinoma have reduced miR-320a, which could function as an antitumor microRNA [81]. In turn, overexpression of miR-320a in CAFs showed inhibition of tumorigenesis [81].

\section{Exosomes-mediated anti-tumor therapies and suppression}

Exosomes have been emerging to be attractive immune modulators in fighting cancer. Exosomes derived from B-cells and dendritic cells have shown the ability to induce antigen-specific $\mathrm{T}$ - and $\mathrm{B}-$ cell responses $[82,83]$. Animal studies of dendritic cell (DC)-derived exosomes showed improved tumor microenvironment by a significant increase in CD8+ $\mathrm{T}$ lymphocytes, elevated levels of IFN- $\gamma$ and interleukin-2, and decrease in CD25+Foxp3+ regulatory $\mathrm{T}$ (Treg) cells and of interleukin- 10 and TGF- $\beta$ in tumor sites [84]. Clinical trials of dendritic cell-derived exosomes showed antitumor immunity in patients with advanced non-small cell lung cancer (NSCLC) through boosting NKp30-dependent NK cell functions [85]. Exosomes derived from NK cells themselves have also been shown to have important therapeutic effects. Both in vivo and in vitro studies demonstrated that NK cellderived exosomes exert cytotoxic effects on melanoma cells by presenting perforin and FasL, both of which are involved in apoptosis [86]. However, lymphocyte-derived exosomes are not the only immune modulators in the TME as TDEs are another source of vaccines for cancer immunotherapy. TDEs can promote immune function and inhibit tumor growth [87]. TDEs from lymphocytic leukemia cells significantly decrease TGF- $\beta 1$ expression of DC cells; in addition, DC cells pulsed with those tumor exosomes can more effectively stimulate CD4+ $\mathrm{T}$ cell proliferation in vitro and Th1 cytokine secretion and induced a tumor-specific CTL response [87]. On the other hand, TDEs can also play a role in promoting tumor growth by immunosuppression. Pancreatic cancer-derived exosomes can decrease HLA-DR expression on CD14+ monocytes through the production of reactive oxidative stress (ROS) [88].

Recent evidence has demonstrated how exosomes are important mediators of intracellular communication in the TME and essential for cancer progression and metastasis $[89,90]$. Cancer cells can produce exosomes full of tumor-promoting signaling molecules, such as $\mathrm{Src}$ tyrosine kinase, insulin-like growth factor 1 receptor (IGFIR), and focal adhesion kinase (FAK) [91] Src, which signals through FAK, has been associated with many aspects of tumor progression, such as cell proliferation, metastasis, and angiogenesis; in addition, Src signaling is known to crosstalk with IGF-IR, which also promotes angiogenesis [91]. TDEs promote angiogenesis through the transfer of long intergenic non-coding RNA CCAT2 (linc-CCAT2) from glioma cells to endothelial cells [92].

RNA molecules are being shown to be common cargo in exosomes. MDSCs with miR-126a exosomes increased the expression of the inflammatory cytokine IL-13 that leads to increased blood vessel formation and promotes lung metastasis of breast cancer [93]. Small interfering RNAs (siRNAs), which have shown strong potential as therapeutic agents but difficult to deliver, are more permeable when loaded in exosomes for drug delivery [94].

As an exosomal cargo includes numerous proteins, lipids, and nucleic acids, valuable information can be garnered from their contents about their origins and function. In part, an effort has been made to characterize exosomes, and specifically TDEs, for use as biomarkers in disease diagnostics and therapeutics, or "theranostics" $[54,95,96]$. In this application, TDEs are collected and isolated from a liquid biopsy, which may include urine or blood serum [97] [98], and their contents are then purified and analyzed. Currently, the gold standard for exosomal purification includes differential centrifugation [96], although exosome isolation is still an active area of research [97, 99]. Biomarkers can be identified and differentiated as either up- or down-regulated through Western blot analysis for proteins or RT-qPCR for nucleic acids [97]. In particular, miRNAs in TDEs have proven useful as a potential source of biomarkers, for their stability, high specificity, and ease of collection [100]. Profile comparisons of miRNAs between tumor tissue 
and TDEs have shown to be highly homologous and can differentiate between benign pancreatic tumors and pancreatic carcinomas [101]. A few advantages of using TDEs include the prevention of invasive procedures to monitor disease and the ability to stratify patients into specific categories for therapy. Exosomal theranostics have already proven useful in detecting tumors of the central nervous system [98], in indicating nephrologies through urine collection and analysis [97], and in placental exosomal detection of preeclampsia [102]. However, although specific in distinguishing among diseases, miRNA analysis of TDEs cannot illustrate the severity of a disease [100]. Its use as a theranostic tool will continue to develop in the field of TDEs and in cancer biology as isolation, purification, and analytical techniques improve. It is projected that exosomes will not only prove useful as biomarkers for early disease detection, but they may also serve as biomarkers to predict a patient's response to drugs [103]. Moreover, fluctuating concentrations of exosomes circulating in the serum, bile, or other organ systems are expected to be useful as biomarkers indicating progression of a disease [104].

\section{CONCLUDING \\ REMARKS AND PERSPECTIVES}

Exosomes are small membrane vesicles that are formed from inward budding of multivesicular endosomes and that then fuse with the plasma membrane resulting in the discharge of the exosomes into the extracellular environment [28-30]. While immunotherapy serves to target TDEs, other modalities of treatment seek to utilize TDEs for their advantageous properties, such as their size, composition, and tumor-targeting capacity [105]. Several current emerging therapies utilizing exosomes include anti-tumor vaccines, delivery vehicles for drugs, and gene therapy. First, TDEs offer a unique approach to develop anti-tumor vaccines due to their integrated function in tumor cell intercommunication. It has been shown that TDEs derived from pancreatic cancer cell lines were able to effectively decrease tumor cell proliferation though downregulation of the Notch-1 signaling pathway and activation of a mitochondria-dependent apoptosis mechanism [106]. These TDEs, rich in lipid rafts, served as signals to decrease the expression of Hes-1, the intranuclear target of Notch-1, which led to apoptosis after a cell cycle arrest in the $\mathrm{G}_{0} \mathrm{G}_{1}$ phase [106]. Besides TDEs, other types of exosomes, such as dendritic cellderived exosomes, could be utilized to target tumors by priming them with tumor-associated antigens and thus eliciting an NK cell response [107, 108]. The small size and structural makeup of exosomes also make them useful in serving as potential nanocarriers for drug delivery. They can be packaged with small molecules, proteins, or nucleic acids and administered to patients, avoiding first pass metabolism of the liver and absorption in the gut, with the ability to cross difficult membranes such as the blood brain barrier [109]. Cytotoxic drugs can also be effectively delivered to target cells without altering their mechanism of action, as illustrated in the delivery of acridine orange to melanoma cells [110]. However, it remains a challenge to be able to properly design exosomes for drug delivery and to avoid an unwanted immune reaction $[109,111]$. The delivery of miRNAs or RNAis via exosomes allows for rapid gene expression in target cells while avoiding the lysosomal pathway through a direct cytosolic delivery [111-113]. In addition, there is evidence of transport and excretion by proteins and lipids by exosomes. Exosomes may transport lipids such as sphingolipids, cholesterol, and ceramide $[114,115]$. Silverman et. al. identified exosome-based secretion as the main mechanism for protein secretion by Leishmania and showed that exosomes deliver proteins to host target cells [116]. Many proteins are found on exosomes that include membrane transport proteins, tetraspannins, heat shock proteins, and multi-vesicular proteins [103, 117].

The biogenesis of exosomes is carried out mainly by 2 types of pathways: endosomal sorting complex required for transport (ESCRT)-dependent and ESCRT independent. The-ESCRT dependent pathway relays on a complex of various proteins as well as certain carbohydrate molecules for the successful biogenesis of exosomes through multi vesicular binding (MVB) formation. ESCRT consists of a five distinct protein complex, namely, ESCRTs 0, I, II, and III, AAA ATPase and Vps4. This process is initiated in the endosomal system [118]. A report by Trajkovic et al. (2008) examined the ESCRT-independent pathway of exosome generation and reported that Ceramide has a significant role in MVB formation [119]. Further, 5 Rab GTPases were reported in the exosome biogenesis from HeLa cells $[118,120]$. Several proteins were involved in the ESCRTindependent pathway, including sphingomylinase-2 [121], sphingosine-1 phosphate receptors [122], transferrin receptors [123], and p53 [124].

A better understanding of exosomes and their role in cancer have led to the development of exosomal theranostics in order to use exosomes for both diagnostic and therapeutic purposes. Exosomes have been gaining notice for their function in the TME, and TDEs, in particular, provide a promising direction for cancer treatment as mechanisms for better drug delivery, tumor suppression, and immunoregulation due to their advantageous size, composition, and homing capabilities (Table 2). Yet the manifold exosomal functions present another face of exosomes as in their role in cancer progression. The development of cancer involves the complex interaction of cells and signaling molecules in the TME and exosomes have been shown to promote tumor growth though the inhibition of anti-tumor immunity and 
the development of angiogenesis. Future research would fully take advantage of exosomes' ubiquitous presence in eukaryotic cells as they appear to provide a plethora of conduits for anti-cancer therapy.

\section{OVERALL}

Due to the complexity of exosomes and their contrasting roles in cancer, several areas need attention, including (1) better methods for isolating cancer exosomes (2) better understanding how the cargos in exosomes are packed particularly that cancer cells are heterogeneous and in each cell the nature of the cargo is different; this will facilitate early diagnosis and response to treatments using exosomes (3) undertaking clinical trials in different types of cancers in order to validate the use of exosomes as diagnostics and therapeutics (4) the identification of biomarkers of exosomes in response to various therapies. (5) the use of exosomes as delivery vehicles for drugs, antigens, nucleic acids, etc., and (6) establishment of GMP facilities for the manufacture, storage, and stability for the administration of therapeutic exosomes of high quality and with high safety.

\section{Abbreviations}

CAF, cancer-associated fibroblast; CD8, cluster of differentiation 8; CD9, cluster of differentiation 9; $\mathrm{CD} 24$, cluster of differentiation 24; CD28, cluster of differentiation 28; CD45, cluster of differentiation 45; DC cell, dendritic cell; EpCAM, epithelial cell adhesion protein; ECM, extracellular matrix; EGFRvIII, epidermal growth factor receptor; Egr-1, early growth response-1; EMT, epithelial mesenchymal transition; ESCRT, endosomal sorting complexes required for transport; FACS, fluorescence-activated cell sorting; FAK, focal adhesion kinase; ICAM-1, intercellular adhesion molecule -1; IGF-IR, insulin-like growth factor 1 receptor; IncRNA, long non-coding RNA; Mart-1, melanoma antigen recognized by T cells 1; MALDI-TOF, matrix-assisted laser desorption ionization-time of flight; Mel-CAM, melanoma cell adhesion molecule; MDSC, myeloid derived suppressor cell; MHC II, Major Histocompatibility Complex Class II; MSF, migration stimulating factor; miRNA, microRNA; NK cells, natural killer cells; NSCLC, non-small cell lung cancer;PGE2, prostaglandin E2; RANTES, regulated on activation, normal $\mathrm{T}$ cell expressed and secreted; siRNA, small-interfering RNA; TDE, tumor-derived exosome; TGF- $\beta$, transforming growth factor $\beta$; TME, tumor microenvironment; Treg, regulatory T cell; VEGFR, Vascular endothelial growth factor

\section{ACKNOWLEDGMENTS}

We acknowledge the Jonsson Comprehensive Cancer Center and the UCLA School of Dentistry for their support.

\section{CONFLICTS OF INTEREST}

The authors declare that the research was conducted in the absence of any commercial or financial relationships that could be construed as a potential conflict of interest.

\section{REFERENCES}

1. Zhang X, Tu H, Yang Y, Fang L, Wu Q, Li J. Mesenchymal Stem Cell-Derived Extracellular Vesicles: Roles in Tumor Growth, Progression, and Drug Resistance. Stem Cells International. 2017; 2017: 12. doi: 10.1155/2017/1758139.

2. Hui L, Chen Y. Tumor microenvironment: Sanctuary of the devil. Cancer Lett. 2015; 368: 7-13. doi: 10.1016/j. canlet.2015.07.039.

3. Sun Y. Tumor microenvironment and cancer therapy resistance. Cancer Lett. 2016; 380: 205-15. doi: 10.1016/j. canlet.2015.07.044.

4. Klemm F, Joyce JA. Microenvironmental regulation of therapeutic response in cancer. Trends Cell Biol. 2015; 25: 198-213. doi: 10.1016/j.tcb.2014.11.006.

5. Hanahan D, Weinberg RA. The Hallmarks of Cancer. Cell. 2000; 100: 57-70. doi: 10.1016/s0092-8674(00)81683-9.

6. Moris D, Beal EW, Chakedis J, Burkhart RA, Schmidt C, Dillhoff M, Zhang X, Theocharis S, Pawlik TM. Role of exosomes in treatment of hepatocellular carcinoma. Surgical Oncology. 2017; 26: 219-28. doi: 10.1016/j. suronc.2017.04.005.

7. Zhao Y, Ting KK, Li J, Cogger VC, Chen J, JohanssonPercival A, Ngiow SF, Holst J, Grau G, Goel S, Muller T, Dejana E, McCaughan G, et al. Targeting Vascular Endothelial-Cadherin in Tumor-Associated Blood Vessels Promotes T-cell-Mediated Immunotherapy. Cancer Res. 2017. doi: 10.1158/0008-5472.CAN-16-3129.

8. Webber JP, Spary LK, Sanders AJ, Chowdhury R, Jiang WG, Steadman R, Wymant J, Jones AT, Kynaston H, Mason MD, Tabi Z, Clayton A. Differentiation of tumourpromoting stromal myofibroblasts by cancer exosomes. Oncogene. 2015; 34: 290-302. doi: 10.1038/onc.2013.560.

9. Dittmer J, Leyh B. The impact of tumor stroma on drug response in breast cancer. Seminars in Cancer Biology. 2015; 31: 3-15. doi: 10.1016/j.semcancer.2014.05.006.

10. Carito V, Bonuccelli G, Martinez-Outschoorn UE, Whitaker-Menezes D, Caroleo MC, Cione E, Howell A, Pestell RG, Lisanti MP, Sotgia F. Metabolic remodeling of the tumor microenvironment: Migration stimulating factor (MSF) reprograms myofibroblasts toward lactate production, fueling anabolic tumor growth. Cell Cycle. 
2012; 11: 3403-14. doi: 10.4161/cc.21701.

11. Moore-Smith LD, Isayeva T, Lee JH, Frost A, Ponnazhagan S. Silencing of TGF- $\beta 1$ in tumor cells impacts MMP-9 in tumor microenvironment. Scientific Reports. 2017; 7: 8678. doi: 10.1038/s41598-017-09062-y.

12. Kang N, Yaqoob U, Geng Z, Bloch K, Liu C, Gomez T, Billadeau D, Shah V. Focal adhesion assembly in myofibroblasts fosters a microenvironment that promotes tumor growth. Am J Pathol. 2010; 177: 1888-900. doi: 10.2353/ajpath.2010.100187.

13. Greening DW, Gopal SK, Xu R, Simpson RJ, Chen W. Exosomes and their roles in immune regulation and cancer. Semin Cell Dev Biol. 2015; 40: 72-81. doi: 10.1016/j. semcdb.2015.02.009.

14. Chen W, Jiang J, Xia W, Huang J. Tumor-Related Exosomes Contribute to Tumor-Promoting Microenvironment: An Immunological Perspective. Journal of Immunology Research. 2017; 2017: 10. doi: 10.1155/2017/1073947.

15. Whiteside TL. Exosomes and tumor-mediated immune suppression. J Clin Invest. 2016; 126: 1216-23. doi: 10.1172/JCI81136.

16. Guo W, Gao Y, Li N, Shao F, Wang C, Wang P, Yang Z, Li R, He J. Exosomes: New players in cancer. Oncology Reports. 2017; 38: 665-75. doi: 10.3892/or.2017.5714.

17. Taylor DD, Gercel-Taylor C. Exosomes/microvesicles: mediators of cancer-associated immunosuppressive microenvironments. Semin Immunopathol. 2011; 33: 44154. doi: 10.1007/s00281-010-0234-8.

18. Sharma A, Khatun Z, Shiras A. Tumor exosomes: cellular postmen of cancer diagnosis and personalized therapy. Nanomedicine (Lond). 2016; 11. doi: 10.2217/nnm.15.210.

19. Zhang B, Yin Y, Lai RC, Lim SK. Immunotherapeutic Potential of Extracellular Vesicles. Frontiers in Immunology. 2014; 5. doi: 10.3389/fimmu.2014.00518.

20. Kahlert C, Kalluri R. Exosomes in tumor microenvironment influence cancer progression and metastasis. J Mol Med (Berl). 2013; 91: 431-7. doi: 10.1007/s00109-013-1020-6.

21. Valadi H, Ekstrom K, Bossios A, Sjostrand M, Lee JJ, Lotvall JO. Exosome-mediated transfer of mRNAs and microRNAs is a novel mechanism of genetic exchange between cells. Nature Cell Biology. 2007; 9: 654-U72. doi: 10.1038/ncb1596.

22. Thery C, Ostrowski M, Segura E. Membrane vesicles as conveyors of immune responses. Nat Rev Immunol. 2009; 9: 581-93. doi: doi:10.1038/nri2567.

23. Fevrier B, Raposo G. Exosomes: endosomal-derived vesicles shipping extracellular messages. Current opinion in cell biology. 2004; 16: 415-21. doi: 10.1016/j. ceb.2004.06.003.

24. Théry C, Regnault A, Garin J, Wolfers J, Zitvogel L, Ricciardi-Castagnoli P, Raposo G, Amigorena S. Molecular characterization of dendritic cell-derived exosomes. The Journal of cell biology. 1999; 147: 599-610. doi: 10.1083/ jcb.147.3.599.
25. Raposo G, Nijman HW, Stoorvogel W, Liejendekker R, Harding CV, Melief CJ, Geuze HJ. B lymphocytes secrete antigen-presenting vesicles. The Journal of Experimental Medicine. 1996; 183: 1161-72. doi: 10.1084/ jem.183.3.1161.

26. Théry C, Boussac M, Véron P, Ricciardi-Castagnoli P, Raposo G, Garin J, Amigorena S. Proteomic analysis of dendritic cell-derived exosomes: a secreted subcellular compartment distinct from apoptotic vesicles. The Journal of Immunology. 2001; 166: 7309-18. doi:10.4049/ jimmunol.166.12.7309.

27. Blanchard N, Lankar D, Faure F, Regnault A, Dumont C, Raposo G, Hivroz C. TCR Activation of Human T Cells Induces the Production of Exosomes Bearing the TCR/

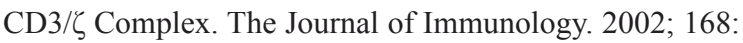
3235-41. doi: 10.4049/jimmunol.168.7.3235.

28. Théry C, Zitvogel L, Amigorena S. Exosomes: composition, biogenesis and function. Nature reviews Immunology. 2002; 2: 569. doi: 10.1038/nri855.

29. Denzer K, Kleijmeer MJ, Heijnen HF, Stoorvogel W, Geuze HJ. Exosome: from internal vesicle of the multivesicular body to intercellular signaling device. Journal of Cell Science. 2000; 113: 3365-74.

30. Mears R, Craven RA, Hanrahan S, Totty N, Upton C, Young SL, Patel P, Selby PJ, Banks RE. Proteomic analysis of melanoma-derived exosomes by twodimensional polyacrylamide gel electrophoresis and mass spectrometry. Proteomics. 2004; 4: 4019-31. doi: 10.1002/ pmic. 200400876.

31. Kahlert C, Kalluri R. Exosomes in tumor microenvironment influence cancer progression and metastasis. Journal of molecular medicine. 2013; 91: 431-7. doi: 10.1007/s00109013-1020-6.

32. Bobrie A, Krumeich S, Reyal F, Recchi C, Moita LF, Seabra MC, Ostrowski M, Théry C. Rab27a supports exosome-dependent and-independent mechanisms that modify the tumor microenvironment and can promote tumor progression. Cancer research. 2012; 72: 4920-30. doi: 10.1158/0008-5472.

33. Wollert T, Hurley JH. Molecular mechanism of multivesicular body biogenesis by ESCRT complexes. Nature. 2010; 464: 864. doi: 10.1038/nature08849.

34. Van Niel G, Raposo G, Candalh C, Boussac M, Hershberg R, Cerf-Bensussan N, Heyman M. Intestinal epithelial cells secrete exosome-like vesicles. Gastroenterology. 2001; 121: 337-49. doi: 10.1053/gast.2001.26263.

35. Raposo G, Tenza D, Mecheri S, Peronet R, Bonnerot C, Desaymard C. Accumulation of major histocompatibility complex class II molecules in mast cell secretory granules and their release upon degranulation. Molecular biology of the cell. 1997; 8: 2631-45. doi: 10.1091/mbc.8.12.2631.

36. Clayton A, Turkes A, Dewitt S, Steadman R, Mason MD, Hallett MB. Adhesion and signaling by B cell-derived exosomes: the role of integrins. The FASEB journal. 2004; 
18: 977-9. doi: 10.1096/fj.03-1094fje.

37. Hendrix A, Hume AN. Exosome signaling in mammary gland development and cancer. International Journal of Developmental Biology. 2011; 55: 879-87. doi: 10.1387/ ijdb.113391ah.

38. Chaput N, Théry C. Exosomes: immune properties and potential clinical implementations. Seminars in Immunopathology. 2011; 33: 419-40. doi: 10.1007/s00281010-0233-9.

39. Al-Nedawi K, Meehan B, Micallef J, Lhotak V, May L, Guha A, Rak J. Intercellular transfer of the oncogenic receptor EGFRvIII by microvesicles derived from tumour cells. Nature cell biology. 2008; 10: 619. doi: 10.1038/ ncb1725.

40. Runz S, Keller S, Rupp C, Stoeck A, Issa Y, Koensgen D, Mustea A, Sehouli J, Kristiansen G, Altevogt P. Malignant ascites-derived exosomes of ovarian carcinoma patients contain CD24 and EpCAM. Gynecologic oncology. 2007; 107: 563-71. doi: 10.1016/j.ygyno.2007.08.064.

41. Swann JB, Smyth MJ. Immune surveillance of tumors. J Clin Invest. 2007; 117: 1137-46. doi: 10.1172/JCI31405.

42. Mantovani A, Allavena P, Sica A, Balkwill F. Cancer-related inflammation. Nature. 2008; 454: 436-44. doi: 10.1038/ nature 07205 .

43. Mincheva-Nilsson L, Baranov V. Cancer exosomes and NKG2D receptor-ligand interactions: impairing NKG2D-mediated cytotoxicity and anti-tumour immune surveillance. Semin Cancer Biol. 2014; 28: 24-30. doi: 10.1016/j.semcancer.2014.02.010.

44. Rock KL, Clark K. Analysis of the role of MHC class II presentation in the stimulation of cytotoxic $\mathrm{T}$ lymphocytes by antigens targeted into the exogenous antigen-MHC class I presentation pathway. Journal of Immunology. 1996; 156: 3721-6.

45. Viaud S, Thery C, Ploix S, Tursz T, Lapierre V, Lantz O, Zitvogel L, Chaput N. Dendritic cell-derived exosomes for cancer immunotherapy: what's next? Cancer Res. 2010; 70: 1281-5. doi: 10.1158/0008-5472.CAN-09-3276.

46. Andre F, Schartz NE, Movassagh M, Flament C, Pautier P, Morice P, Pomel C, Lhomme C, Escudier B, Le Chevalier T, Tursz T, Amigorena S, Raposo G, et al. Malignant effusions and immunogenic tumour-derived exosomes. Lancet. 2002; 360: 295-305. doi: 10.1016/S0140-6736(02)09552-1.

47. Bhatnagar S, Shinagawa K, Castellino FJ, Schorey JS. Exosomes released from macrophages infected with intracellular pathogens stimulate a proinflammatory response in vitro and in vivo. Blood. 2007; 110: 3234-44. doi: 10.1182/blood-2007-03-079152.

48. Obregon C, Rothen-Rutishauser B, Gerber P, Gehr P, Nicod LP. Active uptake of dendritic cell-derived exovesicles by epithelial cells induces the release of inflammatory mediators through a TNF-alpha-mediated pathway. Am J Pathol. 2009; 175: 696-705. doi: 10.2353/ ajpath.2009.080716.
49. Viaud S, Terme M, Flament C, Taieb J, André F, Novault S, Escudier B, Robert C, Caillat-Zucman S, Tursz T. Dendritic cell-derived exosomes promote natural killer cell activation and proliferation: a role for NKG2D ligands and IL-15R $\alpha$. PloS one. 2009; 4: e4942. doi: 10.1371/journal. pone. 0004942 .

50. Ashiru O, Boutet P, Fernandez-Messina L, AgueraGonzalez S, Skepper JN, Vales-Gomez M, Reyburn HT. Natural killer cell cytotoxicity is suppressed by exposure to the human NKG2D ligand MICA*008 that is shed by tumor cells in exosomes. Cancer Res. 2010; 70: 481-9. doi: 10.1158/0008-5472.CAN-09-1688.

51. Szczepanski MJ, Szajnik M, Welsh A, Foon KA, Whiteside TL, Boyiadzis M. Interleukin-15 enhances natural killer cell cytotoxicity in patients with acute myeloid leukemia by upregulating the activating NK cell receptors. Cancer Immunol Immunother. 2010; 59: 73-9. doi: 10.1007/ s00262-009-0724-5.

52. Kalinski P, Okada H. Polarized dendritic cells as cancer vaccines: directing effector-type $\mathrm{T}$ cells to tumors. Semin Immunol. 2010; 22: 173-82. doi: 10.1016/j. smim.2010.03.002.

53. Lee HM, Choi E-J, Kim JH, Kim TD, Kim Y-K, Kang C, Gho YS. A membranous form of ICAM-1 on exosomes efficiently blocks leukocyte adhesion to activated endothelial cells. Biochemical and Biophysical Research Communications. 2010; 397: 251-6. doi: 10.1016/j. bbrc.2010.05.094.

54. Lee $\mathrm{CH}$, Chiang $\mathrm{YH}$, Chang SE, Chong CL, Cheng BM, Roffler SR. Tumor-localized ligation of CD3 and CD28 with systemic regulatory T-cell depletion induces potent innate and adaptive antitumor responses. Clin Cancer Res. 2009; 15: 2756-66. doi: 10.1158/1078-0432.CCR-08-2311.

55. Wieckowski E, Whiteside TL. Human tumor-derived vs dendritic cell-derived exosomes have distinct biologic roles and molecular profiles. Immunologic Research. 2006; 36: 247-54. doi: 10.1385/Ir:36:1:247.

56. Xiang X, Poliakov A, Liu C, Liu Y, Deng ZB, Wang J, Cheng Z, Shah SV, Wang GJ, Zhang L. Induction of myeloid-derived suppressor cells by tumor exosomes. Int J Cancer. 2009; 124. doi: 10.1002/ijc.24249.

57. Liu Y, Xiang X, Zhuang X, Zhang S, Liu C, Cheng Z, Michalek S, Grizzle W, Zhang H-G. Contribution of MyD88 to the Tumor Exosome-Mediated Induction of Myeloid Derived Suppressor Cells. The American Journal of Pathology. 2010; 176: 2490-9. doi: 10.2353/ ajpath.2010.090777.

58. Filipazzi P, Bürdek M, Villa A, Rivoltini L, Huber V. Recent advances on the role of tumor exosomes in immunosuppression and disease progression. Seminars in Cancer Biology. 2012; 22: 342-9. doi: 10.1016/j. semcancer.2012.02.005.

59. Whiteside TL. Immune modulation of T-cell and NK (natural killer) cell activities by TEXs (tumour-derived exosomes). Biochem Soc Trans. 2013; 41: 245-51. doi: 
10.1042/BST20120265.

60. Ludwig S, Floros T, Theodoraki M-N, Hong C-S, Jackson EK, Lang S, Whiteside TL. Suppression of Lymphocyte Functions by Plasma Exosomes Correlates with Disease Activity in Patients with Head and Neck Cancer. Clinical Cancer Research. 2017; 23: 4843-54. doi: 10.1158/10780432.ccr-16-2819.

61. Abusamra AJ, Zhong Z, Zheng X, Li M, Ichim TE, Chin JL, Min WP. Tumor exosomes expressing Fas ligand mediate CD8+ T-cell apoptosis. Blood Cells Mol Dis. 2005; 35: 169-73. doi: 10.1016/j.bcmd.2005.07.001.

62. Andreola G, Rivoltini L, Castelli C, Huber V, Perego P, Deho P, Squarcina P, Accornero P, Lozupone F, Lugini L, Stringaro A, Molinari A, Arancia G, et al. Induction of lymphocyte apoptosis by tumor cell secretion of FasLbearing microvesicles. J Exp Med. 2002; 195: 1303-16. doi: 10.1084/jem.20011624.

63. Kim JW, Wieckowski E, Taylor DD, Reichert TE, Watkins S, Whiteside TL. Fas ligand-positive membranous vesicles isolated from sera of patients with oral cancer induce apoptosis of activated T lymphocytes. Clin Cancer Res. 2005; 11: 1010-20.

64. Taylor DD, Gercel-Taylor C, Lyons KS, Stanson J, Whiteside TL. T-cell apoptosis and suppression of T-cell receptor/CD3-zeta by Fas ligand-containing membrane vesicles shed from ovarian tumors. Clin Cancer Res. 2003; 9: 5113-9.

65. Maybruck BT, Pfannenstiel LW, Diaz-Montero M, Gastman BR. Tumor-derived exosomes induce CD8+ T cell suppressors. Journal for ImmunoTherapy of Cancer. 2017; 5: 65. doi: 10.1186/s40425-017-0269-7.

66. Wieckowski EU, Visus C, Szajnik M, Szczepanski MJ, Storkus WJ, Whiteside TL. Tumor-Derived Microvesicles Promote Regulatory T Cell Expansion and Induce Apoptosis in Tumor-Reactive Activated CD8(+) T Lymphocytes(). Journal of immunology (Baltimore, Md : 1950). 2009; 183: 3720-30. doi: 10.4049/jimmunol.0900970.

67. Vandekeere S, Dewerchin M, Carmeliet P. Angiogenesis Revisited: An Overlooked Role of Endothelial Cell Metabolism in Vessel Sprouting. Microcirculation. 2015; 22: 509-17. doi: 10.1111/micc.12229.

68. Folkman J. (2002). Role of angiogenesis in tumor growth and metastasis. Seminars in oncology: Elsevier), pp. 15-8.

69. Ma W, Xu M, Liu Y, Liu H, Huang J, Zhu Y, Ji LJ, Qi X. Safety profile of combined therapy inhibiting EFGR and VEGF pathways in patients with advanced non-small-cell lung cancer: A meta-analysis of 15 phase II/III randomized trials. Int J Cancer. 2015; 137: 409-19. doi: 10.1002/ ijc. 29377.

70. Yang Y, Liu Q, Lu J, Adah D, Yu S, Zhao S, Yao Y, Qin L, Qin L, Chen X. Exosomes from Plasmodium-infected hosts inhibit tumor angiogenesis in a murine Lewis lung cancer model. Oncogenesis. 2017; 6: e351. doi: 10.1038/ oncsis.2017.52.
71. van Balkom BWM, de Jong OG, Smits M, Brummelman J, den Ouden K, de Bree PM, van Eijndhoven MAJ, Pegtel DM, Stoorvogel W, Würdinger T, Verhaar MC. Endothelial cells require miR-214 to secrete exosomes that suppress senescence and induce angiogenesis in human and mouse endothelial cells. Blood. 2013; 121: 3997-4006. doi: 10.1182/blood-2013-02-478925.

72. Liu C, Yu S, Zinn K, Wang J, Zhang L, Jia Y, Kappes JC, Barnes S, Kimberly RP, Grizzle WE, Zhang H-G. Murine Mammary Carcinoma Exosomes Promote Tumor Growth by Suppression of NK Cell Function. The Journal of Immunology. 2006; 176: 1375-85. doi: 10.4049/ jimmunol.176.3.1375.

73. Lee J-K, Park S-R, Jung B-K, Jeon Y-K, Lee Y-S, Kim M-K, Kim Y-G, Jang J-Y, Kim C-W. Exosomes derived from mesenchymal stem cells suppress angiogenesis by downregulating VEGF expression in breast cancer cells. PloS one. 2013; 8: e84256. doi: 10.1371/journal.pone.0084256.

74. Wu Q, Wu X, Ying X, Zhu Q, Wang X, Jiang L, Chen X, Wu Y, Wang X. Suppression of endothelial cell migration by tumor associated macrophage-derived exosomes is reversed by epithelial ovarian cancer exosomal lncRNA. Cancer Cell Int. 2017; 17: 62. doi: 10.1186/s12935-0170430-x.

75. Nazarenko I, Rana S, Baumann A, McAlear J, Hellwig A, Trendelenburg M, Lochnit G, Preissner KT, Zöller M. Cell Surface Tetraspanin Tspan8 Contributes to Molecular Pathways of Exosome-Induced Endothelial Cell Activation. Cancer Research. 2010; 70: 1668-78. doi: 10.1158/00085472.can-09-2470.

76. Yoon YJ, Kim D-K, Yoon CM, Park J, Kim Y-K, Roh T-Y, Gho YS. Egr-1 Activation by Cancer-Derived Extracellular Vesicles Promotes Endothelial Cell Migration via ERK1/2 and JNK Signaling Pathways. PLoS ONE. 2014; 9: e115170. doi: 10.1371/journal.pone.0115170.

77. Kalluri R, Zeisberg M. Fibroblasts in cancer. Nat Rev Cancer. 2006; 6: 392-401. doi: 10.1038/nrc1877.

78. Sasaki T, Franco OE, Hayward SW. Interaction of prostate carcinoma-associated fibroblasts with human epithelial cell lines in vivo. Differentiation. 2017; 96: 40-8. doi: 10.1016/j.diff.2017.07.002.

79. Donnarumma E, Fiore D, Nappa M, Roscigno G, Adamo A, Iaboni M, Russo V, Affinito A, Puoti I, Quintavalle C, Rienzo A, Piscuoglio S, Thomas R, et al. Cancer-associated fibroblasts release exosomal microRNAs that dictate an aggressive phenotype in breast cancer. Oncotarget. 2017; 8: 19592-608. doi: 10.18632/oncotarget.14752.

80. Chen Y, Zeng C, Zhan Y, Wang H, Jiang X, Li W. Aberrant low expression of $\mathrm{p} 85 \mathrm{alpha}$ in stromal fibroblasts promotes breast cancer cell metastasis through exosome-mediated paracrine Wnt10b. Oncogene. 2017. doi: 10.1038/ onc.2017.100.

81. Zhang Z, Li X, Sun W, Yue S, Yang J, Li J, Ma B, Wang J, Yang X, Pu M, Ruan B, Zhao G, Huang Q, et al. Loss of exosomal miR-320a from cancer-associated fibroblasts 
contributes to HCC proliferation and metastasis. Cancer Lett. 2017; 397: 33-42. doi: 10.1016/j.canlet.2017.03.004.

82. Bell BM, Kirk ID, Hiltbrunner S, Gabrielsson S, Bultema JJ. Designer exosomes as next-generation cancer immunotherapy. Nanomedicine: Nanotechnology, Biology and Medicine. 2016; 12: 163-9. doi: 10.1016/j. nano.2015.09.011.

83. Pitt JM, Charrier M, Viaud S, André F, Besse B, Chaput N, Zitvogel L. Dendritic cell-derived exosomes as immunotherapies in the fight against cancer. The Journal of Immunology. 2014; 193: 1006-11. doi: 10.4049/ jimmunol.1400703.

84. Lu Z, Zuo B, Jing R, Gao X, Rao Q, Liu Z, Qi H, Guo $H$, Yin H. Dendritic cell-derived exosomes elicit tumor regression in autochthonous hepatocellular carcinoma mouse models. Journal of Hepatology. 2017. doi: 10.1016/j. jhep.2017.05.019.

85. Besse B, Charrier M, Lapierre V, Dansin E, Lantz O, Planchard D, Le Chevalier T, Livartoski A, Barlesi F, Laplanche A, Ploix S, Vimond N, Peguillet I, et al. Dendritic cell-derived exosomes as maintenance immunotherapy after first line chemotherapy in NSCLC. OncoImmunology. 2016; 5: e1071008. doi: 10.1080/2162402X.2015.1071008.

86. Zhu L, Kalimuthu S, Gangadaran P, Oh JM, Lee HW, Baek SH, Jeong SY, Lee S-W, Lee J, Ahn B-C. Exosomes Derived From Natural Killer Cells Exert Therapeutic Effect in Melanoma. THERANOSTICS. 2017; 7: 2732-45. doi: $10.7150 /$ thno. 18752 .

87. Huang F, Wan J, Hao S, Deng X, Chen L, Ma L. TGF- $\beta 1$ silenced leukemia cell-derived exosomes target dendritic cells to induce potent anti-leukemic immunity in a mouse model. Cancer Immunology, Immunotherapy. 2017. doi: 10.1007/s00262-017-2028-5.

88. Javeed N, Gustafson MP, Dutta SK, Lin Y, Bamlet WR, Oberg AL, Petersen GM, Chari ST, Dietz AB, Mukhopadhyay D. Immunosuppressive CD14+HLADRlo/neg monocytes are elevated in pancreatic cancer and "primed" by tumor-derived exosomes. OncoImmunology. 2017; 6: e1252013. doi: 10.1080/2162402X.2016.1252013.

89. Luo Z, Wang Q, Lau WB, Lau B, Xu L, Zhao L, Yang H, Feng M, Xuan Y, Yang Y, Lei L, Wang C, Yi T, et al. Tumor microenvironment: The culprit for ovarian cancer metastasis? Cancer Letters. 377: 174-82. doi: 10.1016/j. canlet.2016.04.038.

90. Li X, Wang X. The emerging roles and therapeutic potential of exosomes in epithelial ovarian cancer. Molecular Cancer. 2017; 16: 92. doi: 10.1186/s12943-017-0659-y.

91. DeRita RM, Zerlanko B, Singh A, Lu H, Iozzo RV, Benovic JL, Languino LR. c-Src, Insulin-Like Growth Factor I Receptor, G-Protein-Coupled Receptor Kinases and Focal Adhesion Kinase are Enriched Into Prostate Cancer Cell Exosomes. Journal of Cellular Biochemistry. 2017; 118: 66-73. doi: 10.1002/jcb.25611.

92. Lang H-L, Hu G-W, Zhang B, Kuang W, Chen Y, Wu L, $\mathrm{Xu}$ G-H. Glioma cells enhance angiogenesis and inhibit endothelial cell apoptosis through the release of exosomes that contain long non-coding RNA CCAT2. Oncology Reports. 2017; 38: 785-98. doi: 10.3892/or.2017.5742.

93. Deng Z, Rong Y, Teng Y, Zhuang X, Samykutty A, Mu J, Zhang L, Cao P, Yan J, Miller D, Zhang H-G. Exosomes miR-126a released from MDSC induced by DOX treatment promotes lung metastasis. Oncogene. 2017; 36: 639-51. doi: 10.1038/onc.2016.229.

94. Yang T, Fogarty B, LaForge B, Aziz S, Pham T, Lai L, Bai S. Delivery of small interfering RNA to inhibit vascular endothelial growth factor in zebrafish using natural brain endothelia cell-secreted exosome nanovesicles for the treatment of brain cancer. The AAPS journal. 2017; 19: 475-86. doi: 10.1208/s12248-016-0015-y.

95. Caruso Bavisotto C, Cappello F, Macario AJL, Conway de Macario E, Logozzi M, Fais S, Campanella C. Exosomal HSP60: a potentially useful biomarker for diagnosis, assessing prognosis, and monitoring response to treatment. Expert Review of Molecular Diagnostics. 2017; 17: 815-22. doi: 10.1080/14737159.2017.1356230.

96. Panagiotara A, Markou A, Lianidou ES, Patrinos GP, Katsila T. Exosomes: A Cancer Theranostics Road Map. Public Health Genomics. 2017. doi: 10.1159/000478253.

97. Street JM, Koritzinsky EH, Glispie DM, Yuen PST. (2017). Urine Exosome Isolation and Characterization. In: Gautier J-C, ed. Drug Safety Evaluation: Methods and Protocols. (New York, NY: Springer New York), pp. 413-23.

98. Khan IN, Ullah N, Hussein D, Saini KS. Current and emerging biomarkers in tumors of the central nervous system: Possible diagnostic, prognostic and therapeutic applications. Seminars in Cancer Biology. 2017. doi: 10.1016/j.semcancer.2017.07.004.

99. Vella LJ, Scicluna BJ, Cheng L, Bawden EG, Masters CL, Ang C-S, Willamson N, McLean C, Barnham KJ, Hill AF. A rigorous method to enrich for exosomes from brain tissue. Journal of Extracellular Vesicles. 2017; 6: 1348885. doi: 10.1080/20013078.2017.1348885.

100. Inamdar S, Nitiyanandan R, Rege K. Emerging applications of exosomes in cancer therapeutics and diagnostics. Bioengineering \& Translational Medicine. 2017; 2: 70-80. doi: 10.1002/btm2.10059.

101. Que R, Ding G, Chen J, Cao L. Analysis of serum exosomal microRNAs and clinicopathologic features of patients with pancreatic adenocarcinoma. World Journal of Surgical Oncology. 2013; 11: 219-. doi: 10.1186/1477-7819-11-219.

102. Salomon C, Guanzon D, Scholz-Romero K, Longo S, Correa P, Illanes SE, Rice GE. Placental exosomes as early biomarker of preeclampsia-Potential role of exosomal microRNAs across gestation. The Journal of Clinical Endocrinology \& Metabolism. 2017. doi: 10.1210/jc.201700672.

103. Sundararajan V, Sarkar FH, Ramasamy TS. The versatile role of exosomes in cancer progression: diagnostic and therapeutic implications. Cellular Oncology. 2018: 1-30. doi: 10.1007/s13402-018-0378-4. 
104. He C, Zheng S, Luo Y, Wang B. Exosome Theranostics: Biology and Translational Medicine. Theranostics. 2018; 8: 237. doi: 10.7150/thno.21945.

105. Bastos N, Ruivo CF, Silva S, Melo SA. Exosomes in Cancer: Use them or Target them? Seminars in Cell \& Developmental Biology. doi: 10.1016/j. semcdb.2017.08.009.

106. Ristorcelli E, Beraud E, Mathieu S, Lombardo D, Verine A. Essential role of Notch signaling in apoptosis of human pancreatic tumoral cells mediated by exosomal nanoparticles. International Journal of Cancer. 2009; 125: 1016-26. doi: 10.1002/ijc.24375.

107. Escudier B, Dorval T, Chaput N, André F, Caby M-P, Novault S, Flament C, Leboulaire C, Borg C, Amigorena S, Boccaccio C, Bonnerot C, Dhellin O, et al. Vaccination of metastatic melanoma patients with autologous dendritic cell (DC) derived-exosomes: results of thefirst phase I clinical trial. Journal of Translational Medicine. 2005; 3: 10-. doi: 10.1186/1479-5876-3-10.

108. Tan A, Pena H, Seifalian AM. The application of exosomes as a nanoscale cancer vaccine. Int J Nanomedicine. 2010; 5. doi: $10.2147 /$ IJN.S13402.

109. Ha D, Yang N, Nadithe V. Exosomes as therapeutic drug carriers and delivery vehicles across biological membranes: current perspectives and future challenges. Acta Pharmaceutica Sinica B. 2016; 6: 287-96. doi: 10.1016/j. apsb.2016.02.001.

110. Iessi E, Logozzi M, Lugini L, Azzarito T, Federici C, Spugnini EP, Mizzoni D, Di Raimo R, Angelini DF, Battistini L, Cecchetti S, Fais S. Acridine Orange/ exosomes increase the delivery and the effectiveness of Acridine Orange in human melanoma cells: A new prototype for theranostics of tumors. Journal of Enzyme Inhibition and Medicinal Chemistry. 2017; 32: 648-57. doi: 10.1080/14756366.2017.1292263.

111. Tran T-H, Mattheolabakis G, Aldawsari H, Amiji M. Exosomes as nanocarriers for immunotherapy of cancer and inflammatory diseases. Clinical Immunology. 2015; 160: 46-58. doi: 10.1016/j.clim.2015.03.021.

112. J O'Loughlin A, A Woffindale C, JA Wood M. Exosomes and the emerging field of exosome-based gene therapy. Current gene therapy. 2012; 12: 262-74. doi: $10.2174 / 156652312802083594$.

113. György B, Maguire CA. Extracellular vesicles: nature's nanoparticles for improving gene transfer with adenoassociated virus vectors. Wiley Interdisciplinary Reviews: Nanomedicine and Nanobiotechnology. 2017. doi: 10.1002/ wnan.1488.

114. Azmi AS, Bao B, Sarkar FH. Exosomes in cancer development, metastasis, and drug resistance: a comprehensive review. Cancer Metastasis Rev. 2013; 32: 623-42. doi: 10.1007/s10555-013-9441-9.

115. Record M, Carayon K, Poirot M, Silvente-Poirot S. Exosomes as new vesicular lipid transporters involved in cell-cell communication and various pathophysiologies. Biochim Biophys Acta. 2014; 1841: 108-20. doi: 10.1016/j. bbalip.2013.10.004.

116. Silverman JM, Clos J, de'Oliveira CC, Shirvani O, Fang Y, Wang C, Foster LJ, Reiner NE. An exosome-based secretion pathway is responsible for protein export from Leishmania and communication with macrophages. J Cell Sci. 2010; 123: 842-52. doi: 10.1242/jcs.056465.

117. Vlassov AV, Magdaleno S, Setterquist R, Conrad R. Exosomes: current knowledge of their composition, biological functions, and diagnostic and therapeutic potentials. Biochim Biophys Acta. 2012; 1820: 940-8. doi: 10.1016/j.bbagen.2012.03.017.

118. Rajagopal, C. \& Harikumar, KB. "The Origin and Functions of exosomes in Cancer." Frontiers in oncology 8 (2018): 66. doi: 10.3389/fonc.2018.00066.

119. Trajkovic K, Hsu C, Chiantia S, Rajendran L, Wenzel D, Wieland F, Schwille P, Brügger B, Simons M. Ceramide triggers budding of exosome vesicles into multivesicular endosomes. Science. 2008;319:1244-7. doi: 10.1126/ science. 1153124.

120. Ostrowski M, Carmo NB, Krumeich S, Fanget I, Raposo G, Savina A, Moita CF, Schauer K, Hume AN, Freitas RP, Goud B, Benaroch P, Hacohen N, Fukuda M, Desnos C, Seabra MC, Darchen F, Amigorena S, Moita LF, Thery C. Rab27a and Rab27b control different steps of the exosome secretion pathway. Nat Cell Biol. 2010;12:19-30; sup pp 1-13. doi: $10.1038 / \mathrm{ncb} 2000$.

121. Kosaka N, Iguchi H, Hagiwara K, Yoshioka Y, Takeshita F, Ochiya T. Neutral sphingomyelinase 2 (nSMase2)dependent exosomal transfer of angiogenic microRNAs regulate cancer cell metastasis. J Biol Chem. 2013 Apr 12;288:10849-59. doi: 10.1074/jbc.M112.446831.

122. Kajimoto T, Okada T, Miya S, Zhang L, Nakamura S. Ongoing activation of sphingosine 1-phosphate receptors mediates maturation of exosomal multivesicular endosomes. Nat Commun. 2013;4:2712. doi: 10.1038/ ncomms 3712 .

123. Savina A, Furlán M, Vidal M, Colombo MI. Exosome release is regulated by a calcium-dependent mechanism in K562 cells. J Biol Chem. 2003;278:20083-90. doi: 10.1074/ jbc.M301642200.

124. Lehmann BD, Paine MS, Brooks AM, McCubrey JA, Renegar RH, Wang R, Terrian DM. Senescence-associated exosome release from human prostate cancer cells. Cancer Res. 2008 Oct 1;68:7864-71. doi: 10.1158/0008-5472. CAN-07-6538. 